\title{
Proctitis cystica profunda diagnosed by endoscopic submucosal dissection: use of a therapeutic proce- dure for diagnosis
}

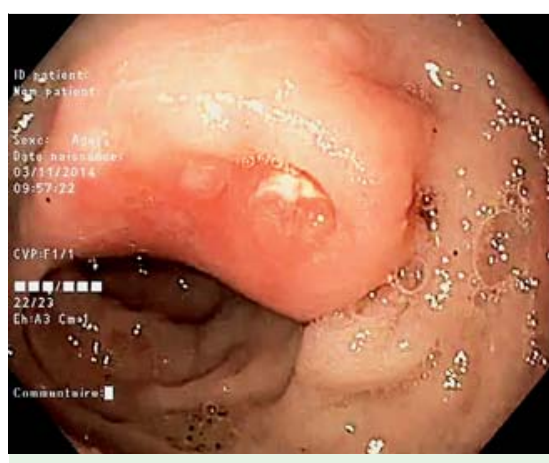

Fig. 1 Submucosal rectal lesion with superficial inflammation in a 54-year-old woman who had developed a massive hematochezia 1 month prior to undergoing colonoscopy.

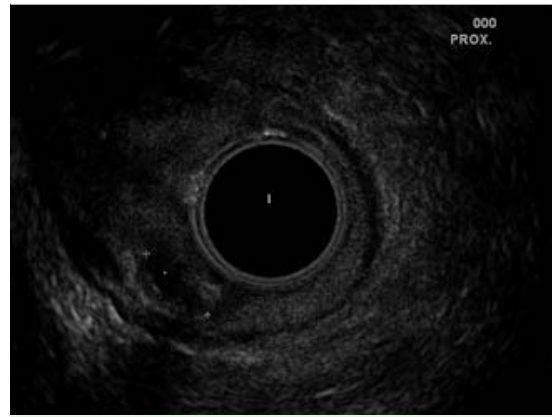

Fig. 2 Ultrasonographic features of a submucosal rectal lesion with a hypoechoic cyst in the third hyperechoic layer.

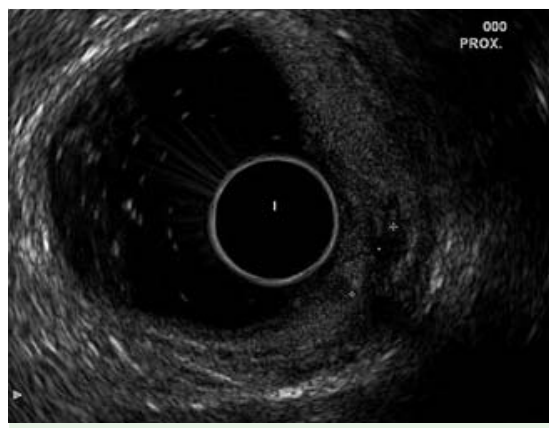

Fig. 3 Ultrasonographic features of a second submucosal rectal lesion with a hypoechoic cyst and hyperechoic calcification with acoustic shadowing.

A 54-year-old woman was referred to our gastroenterology unit after discovery of an atypical submucosal rectal lesion. She had developed massive hematochezia 1 month previously. Colonoscopy revealed $3-\mathrm{cm}$ discrete submucosal lesions with superficial mucosal inflam-
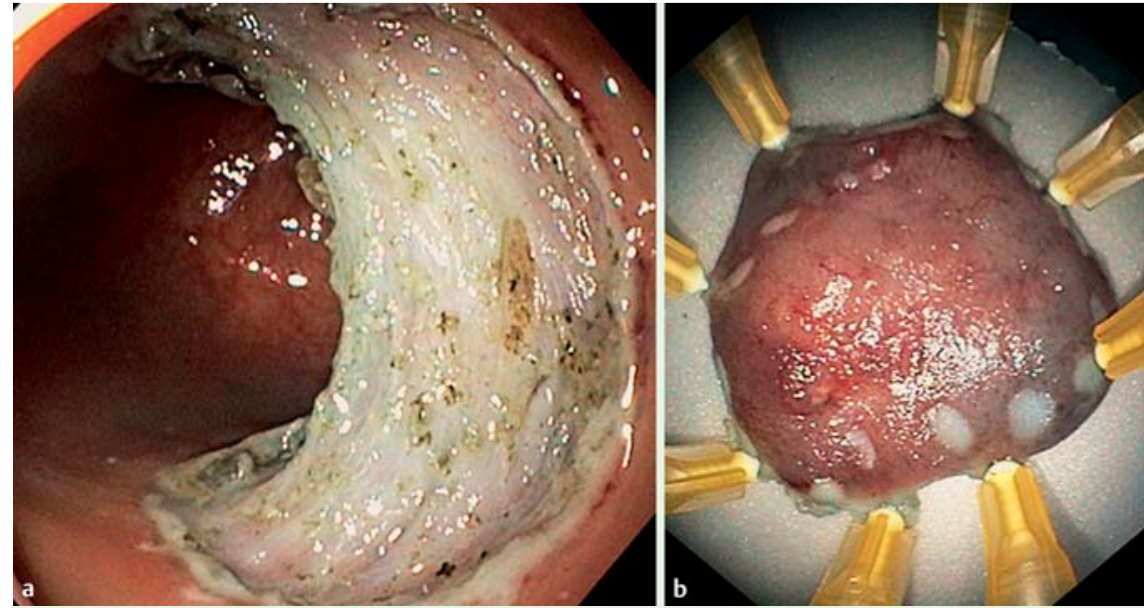

Fig. 4 a Scar after the endoscopic resection of a submucosal rectal lesion. b Macroscopic appearance of the resected specimen.

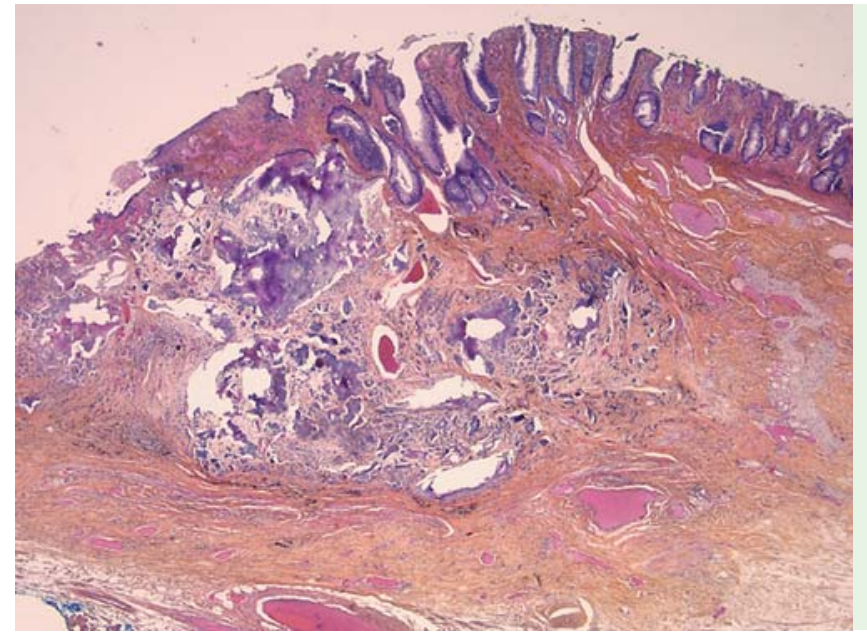

Fig. 5 Pathological analysis showing displaced glands forming submucosal cysts, from the rectum of a 54-year-old woman. Sometimes the cyst lining disappears because of pressure atrophy from large intracystic mucinous accumulations (hematoxylin erythrosine saffron stain, magnification $\times 25$ ).

mation ( Fig. 1). Pathologic analysis of a superficial biopsy specimen was inconclusive. Two successive rectal endoscopic ultrasonographic examinations were performed with a 1-month interval, and hypoechoic cystic lesions of the submucosal layer (third hyperechoic layer) were discovered ( $\bullet$ Fig.2). All submucosal lesions had the same ultrasonographic features, but one exhibited a hyperechoic area with acoustic shadowing typical of calcification ( Fig. 3). Endoscopic biopsies were again inconclusive, and endoscopic ultrasound guided-fine needle aspiration (EUS-FNA) was not performed because of the high risk of infection. Instead, we performed endoscopic submucosal dissection of one lesion to obtain a complete pathological analysis ( $\bullet$ Video 1, $\bullet$ Fig.4). A diagnosis of proctitis cystica profunda was made based on typical pathological features (๑ Fig. 5 and $\bullet$ Fig. 6 ).

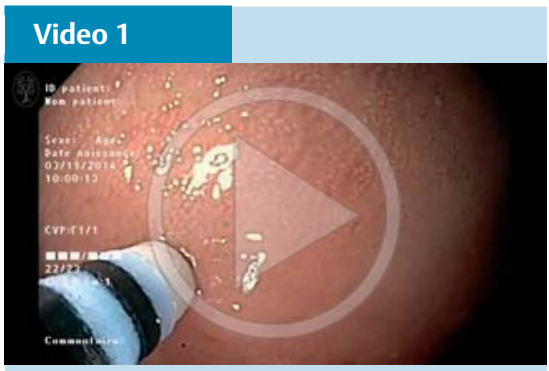

Proctitis cystica profunda diagnosed by endoscopic submucosal dissection. 


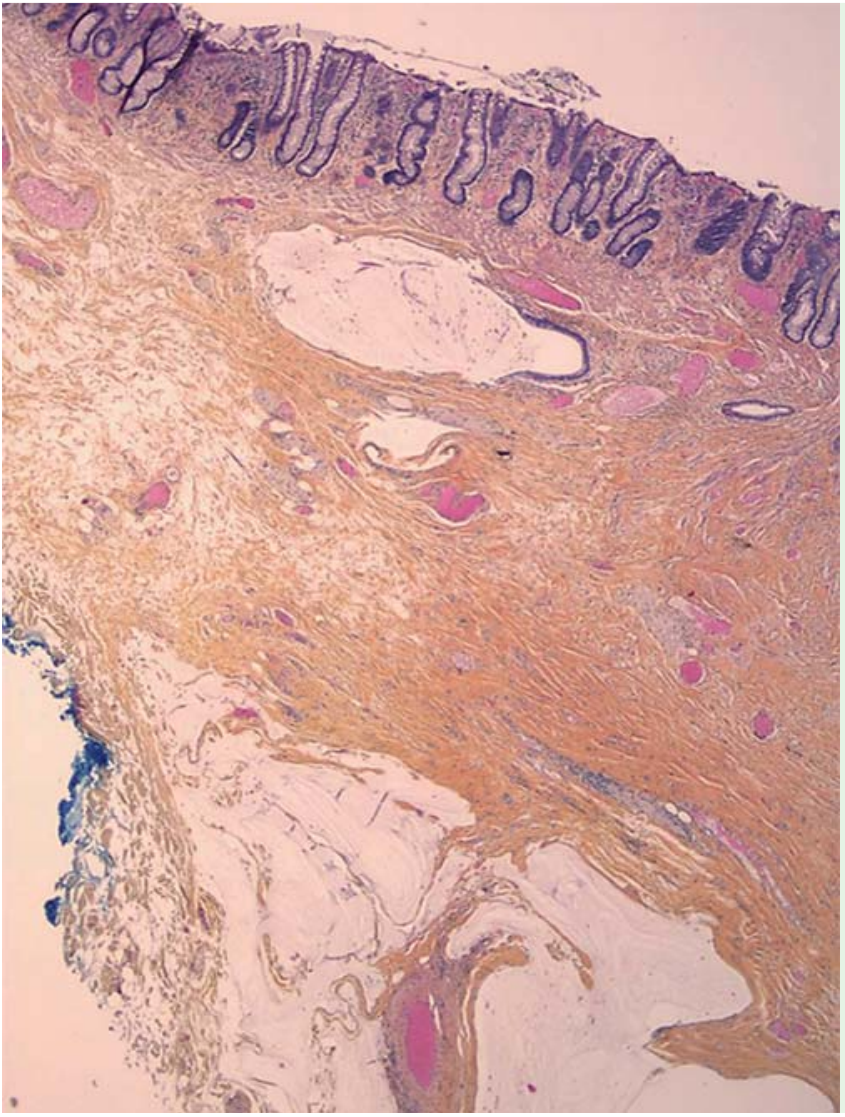

Fig. 6 Pathological analysis of submucosal cysts from the rectum of a 54-year-old woman. The material in the cysts may calcify. (hematoxylin erythrosine saffron stain, magnification $\times 25$ ).

Submucosal lesions are less frequent in the rectum than in the upper gastrointestinal tract, and both diagnosis and treatment can be challenging. EUS plays a key role in such situations [1], particularly for lesions with an intramural origin such as lipomas, leiomyomas, gastrointestinal stromal tumors, and neuroendocrine tumors. Intramural cystic lesions are more challenging to diagnose because of the risk of infection associated with transrectal EUS-FNA, and pathological analysis remains the gold standard. Proctitis cystica profunda is a rare condition that presents as a localized lesion or, diffusely, as multiple lesions [2,3]. Cysts develop in the submucosa or muscularis mucosa. Older cysts often lack an epithelial lining and are surrounded by fibrous tissue and/or a polymorphic inflammatory infiltrate or hemothus avoiding riskier surgery.

Endoscopy_UCTN_Code_TTT_1AQ_2AD

Competing interests: None

\section{Jérémie Jacques ${ }^{1}$, Laura Mesturoux ${ }^{2}$, Paul Carrier ${ }^{1}$, Tessa Tabouret ${ }^{1}$, Veronique Loustaud-Ratti ${ }^{1}$, Denis Sautereau ${ }^{1}$, Romain Legros ${ }^{1}$}

1 Service d'Hépato-gastro-entérologie, CHU Dupuytren, Limoges, France

2 Service d'Anatomopathologie, CHU Dupuytren, Limoges, France

\section{References}

1 Purysko AS, Coppa CP, Kalady MF et al. Benign and malignant tumors of the rectum and perirectal region. Abdom Imaging 2014; 39: 824-852

2 Valenzuela M, Martín-Ruiz JL, Alvarez-Cienfuegos $E$ et al. Colitis cystica profunda: imaging diagnosis and conservative treatment: report of two cases. Dis Colon Rectum 1996; 39: 587-590

3 Guest CB, Reznick RK. Colitis cystica profunda. Review of the literature. Dis Colon Rectum 1989; 32: $983-988$

4 Noffsinger A, Fenoglio-Preiser CM, Maru D et al. Gastrointestinal diseases (Atlas of nontumor pathology). 1st edn. Washington, DC: American Registry of Pathology; 2008: $218-220$

\section{Bibliography}

DOI http://dx.doi.org/

10.1055/s-0034-1392026

Endoscopy 2015; 47: E255-E256

(c) Georg Thieme Verlag KG

Stuttgart · New York

ISSN 0013-726X

cify [4]. Fibrosis is usually moderate, but can be significant in some cases. The presence of these lesions within the rectum is often associated with prolapse and solitary ulcer formation. Differential diagnoses include invasive mucinous carcinoma and, in women, endometriosis. EUS may be diagnostic for submucosal cysts associated with calcification. In summary, we have reported the first case involving one-stage endoscopic submucosal dissection for both pathological diagnosis and resection of proctitis cystica profunda, 